\title{
Intramolecular Additions of Various $\pi$-Nucleophiles to Chemoselectively Activated Amides and Application to the Synthesis of $( \pm)$-Tashiromine
}

\author{
Guillaume Bélanger,* Robin Larouche-Gauthier, Frédéric Ménard, Miguel Nantel, ${ }^{\dagger}$ and \\ Francis Barabé \\ Laboratoire de synthèse organique et de développement de stratégies de synthèse Département de Chimie, \\ Université de Sherbrooke 2500 boulevard Université, Sherbrooke, Québec, J1K 2R1, Canada \\ guillaume.belanger@usherbrooke.ca
}

Received October 13, 2005

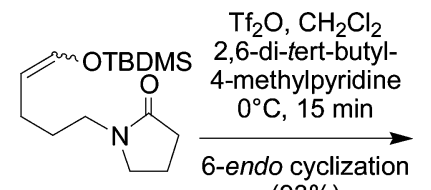

$(93 \%)$

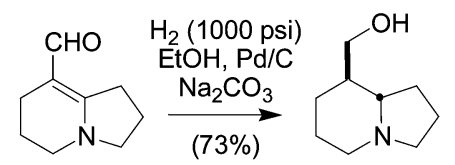

(士)-Tashiromine

Vilsmeier-Haack type cyclizations proved to be particularly efficient for generating parts of the polycyclic cores of many alkaloids, although only monocyclizations have so far been reported. With the goal of rapidly and efficiently constructing polycyclic alkaloids, we decided to exploit the Vilsmeier-Haack reaction by utilizing iminium ions successively generated and trapped with tethered nucleophiles. To develop such a strategy, we had to set the first cyclization. This constitutes a great challenge in itself because amide activation conditions are usually not compatible with tethered nucleophiles, except for indoles and aromatic rings which have already been reported. This paper describes the comprehensive study of intramolecular addition of silyl enol ethers, allylsilanes, and enamines to chemoselectively activated formamides, aliphatic amides, and lactams. Good to excellent yields were obtained for the 5-exo, 6-exo, and 6-endo modes of cyclization. Moreover, we demonstrated that the species in solution after the cyclization are iminium ions. This is highly encouraging for the development of bis-cyclization strategies. An expeditious total synthesis of $( \pm)$-tashiromine is also reported.

\section{Introduction}

Alkaloid natural products have very diverse structures, many of which are polycyclic, and show an extremely wide span of interesting biological activities. This renders alkaloids very attractive to synthetic chemists and has been a great source of motivation for the finding of synthetic strategies and reactions to construct such complex molecules. In that sense, iminium ions are certainly among the functional groups most widely used in total syntheses of alkaloids, especially the intramolecular Mannich reaction, or Mannich cyclization, which proved to be extremely efficient at putting together the heterocyclic skeleton of numerous alkaloids. ${ }^{1}$ Numerous methods of generating iminium ions for the Mannich reaction have been developed

${ }^{\dagger}$ Current address: MDS Pharma Services, 2350, rue Cohen, St-Laurent (Montréal), Québec, H4R 2N6, Canada.

(1) (a) Iminium Salts in Organic Chemistry; Böhme, H., Viehe, H. G., Eds.; Wiley: New York, 1976, part I; 1979, part 2. (b) Overman, L. E.; Ricca, D. J. In Comprehensive Organic Synthesis; Trost, B. M., Flemming, I., Heathcock, C. H., Eds; Pergamon: Oxford, UK, 1991; Vol. 2, p 1007. over the years, ${ }^{2}$ and these iminium ions are of oxidation state II (two C-heteroatom bonds) by definition. The use of iminium ions of a higher oxidation state are known as the VilsmeierHaack reaction. These iminium ions are usually derived from amides, by various activation means employing oxophilic reagents. ${ }^{3,4}$

(2) (a) Arend, M.; Westermann, B.; Risch, N. Angew. Chem., Int. Ed. 1998, 37, 1044. (b) Royer, J.; Bonin, M.; Micouin, L. Chem. Rev. 2004, $104,2311$.

(3) For various amide activation conditions, see: (a) Nishiyama, H.; Nagase, H.; Ohno, K. Tetrahedron Lett. 1979, 48, 4671. (b) Keck, G. E.; McLaws, M. D.; Wager, T. T. Tetrahedron 2000, 56, 9875. See also references cited in: (c) Kuhnert, N.; Clemens, I.; Walsh, R. Org. Biomol. Chem. 2005, 3, 1694. (d) Smith, D. C.; Lee, S. W.; Fuchs, P. L. J. Org. Chem. 1994, 59, 348.

(4) For addition of heteroatomic nucleophiles to activated amides, see: (a) Charette, A. B.; Chua, P. Synlett 1998, 163. (b) Charette, A. B.; Chua, P. Tetrahedron Lett. 1997, 38, 8499. (c) Charette, A. B.; Chua, P. J. Org. Chem. 1998, 63, 908. (d) Charette, A. B.; Grenon, M. Tetrahedron Lett. 2000, 41, 1677. (e) Sforza, S.; Dossena, A.; Corradini, R.; Virgili, E.; Marchelli, R. Tetrahedron Lett. 1998, 39, 711. (f) Thomas, E. W. Synthesis 1993, 767.

10.1021/jo052141v CCC: $\$ 33.50$ @ 2006 American Chemical Society Published on Web 12/08/2005 


\section{SCHEME 1. Planned Biscyclization Strategy}
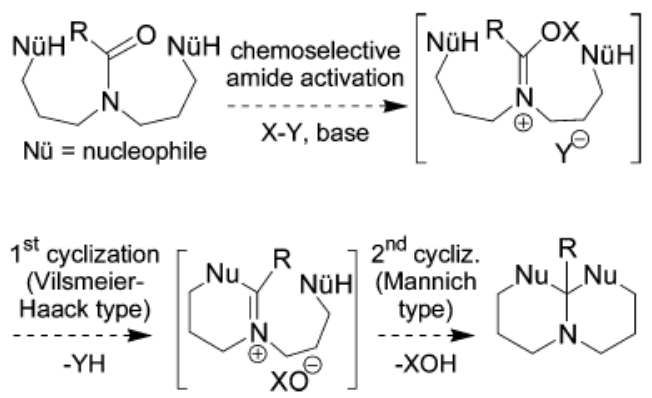

A screening of the literature revealed that iminium ions of both oxidation states are only used in monocyclizations, which is a limit inherent in the oxidation state of the iminium ion only in the Mannich cyclization. However, the higher oxidation state of the iminium ion in the Vilsmeier-Haack type cyclization incited us to exploit the idea of performing two sequential cyclizations in a single operation utilizing iminium ions successively generated and trapped with tethered nucleophiles (NüH, Scheme 1). This strategy offers the possibility of generating polycyclic alkaloid skeletons in one step from simple amide substrates. A very limited number of sequential iminium ion cyclizations have been reported, but these cyclizations were not performed on the same iminium carbon. ${ }^{5}$ Our strategy would thus additionally allow for the creation of a tertiary or a quaternary center $\alpha$ to nitrogen in the final product from an initial secondary of tertiary amide, respectively. Because the cyclization substrates are made from amides or lactams, connections of diverse branches containing the nucleophiles should be facile using well-known chemistry. Modulations of the branches and their position could furthermore lead to a vast assortment of polycyclic alkaloid skeletons, rendering such a strategy highly attractive for its straightforwardness and potential application in total synthesis.

A major challenge to the development of our strategy is, however, to find chemoselective amide activation conditions compatible with the required tethered nucleophiles. The amide activation conditions generally use, or generate during the reaction, Lewis or Bronsted acids ${ }^{3}$ that would easily destroy or deactivate nucleophiles such as vinylsilanes, allylsilanes, enol ethers, enamines, amines, thiols, alcohols, etc. This is probably why only indoles ${ }^{6}$ or activated benzene rings ${ }^{7}$ have been so far reported to intramolecularly trap activated amides, whereas all other reported nucleophiles are externally added once the amide activation is completed. $4,3 \mathrm{~d}$

We recently published our preliminary successful results for amide activation and cyclization with tethered carbon nucleophiles other than indoles or benzene rings. ${ }^{8}$ We now wish to report the full account of this work emphasizing general trends that emerged from detailed comparisons between the different nucleophiles we used, the nature of the amide substrates, and ring sizes generated.

(5) For selected examples, see: (a) Jackson, A. H.; Shannon, P. V. R. Wilkins, D. J. Tetrahedron Lett. 1987, 28, 4901. (b) He, F.; Bo, Y.; Altom, D.; Corey, E. J. J. Am. Chem. Soc. 1999, 121, 6771.

(6) Typically the Bischler-Napieralski cyclization: Bischler, A. Napieralski, B. Chem. Ber. 1893, 26, 903.

(7) (a) Marson, C. M. Tetrahedron 1992, 48, 3659. (b) Martinez, A. G.; Alvarez, R. M.; Barcina, J. O.; Cerero, S. M.; Vilar, E. T.; Fraile, A. G.; Hanack, M.; Subramanian, L. R. J. Chem. Soc., Chem. Commun. 1990, 1571.

(8) Bélanger, G.; Larouche-Gauthier, R.; Ménard, F.; Nantel, M.; Barabé, F. Org. Lett. 2005, 7, 4431.
SCHEME 2. Representative Chemoselective Amide Activation and Nucleophilic Cyclization
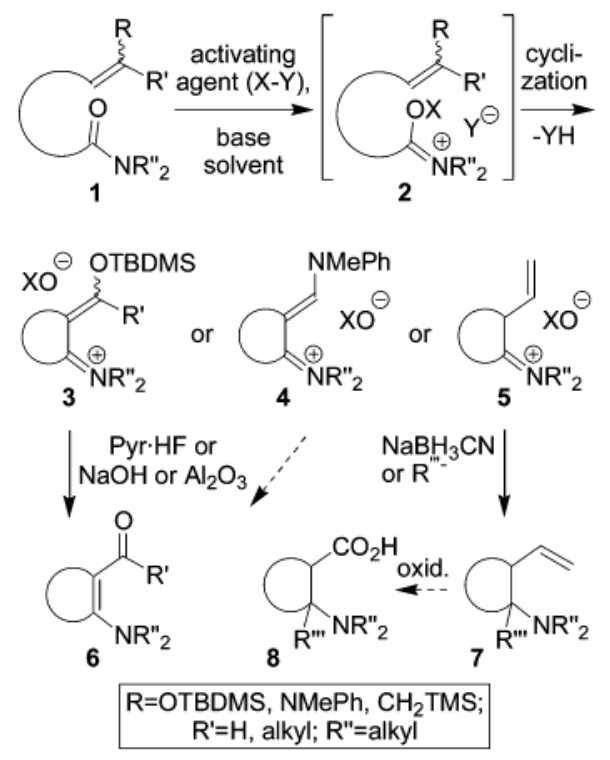

The key reaction is presented in Scheme 2 with a representative amide substrate $\mathbf{1}$ tethered to a $\pi$-nucleophile. When the nucleophile is an aldehydic silyl enol ether (1, R = OTBDMS, $\left.\mathrm{R}^{\prime}=\mathrm{H}\right)$ or a ketonic silyl enol ether $\left(1, \mathrm{R}=\right.$ OTBDMS, $\mathrm{R}^{\prime}=$ alkyl), a cyclic enaminal or enaminone ${ }^{9} 6$ is formed, respectively. Enamines $(1, \mathrm{R}=\mathrm{NMePh})$ lead to vinylogous amidinium ions 4 , that could for instance be hydrolyzed to the corresponding enaminals 6 , whereas allylsilanes $\left(1, \mathrm{R}=\mathrm{CH}_{2} \mathrm{TMS}\right)$ lead to amines $7 \alpha$ to a tertiary $\left(\mathrm{NaBH}(\mathrm{OAc})_{3}\right.$ quench, $\left.\mathrm{R}^{\prime \prime \prime}=\mathrm{H}\right)$ or potentially quaternary center (C-nucleophile addition, $\mathrm{R}^{\prime \prime \prime}=$ alkyl), which could both be derived to the corresponding chiral $\beta$-amino acids $\mathbf{8}$.

\section{Results and Discussion}

The following sections will first describe the syntheses of all of the cyclization substrates, followed by the optimization of the amide activation-cyclization conditions on a particular substrate and the application of these conditions to the intramolecular 5-exo, 6-exo, 5-endo, and 6-endo additions of tethered silyl enol ethers, allylsilanes, and enamines to chemoselectively activated amides and lactams. An application of our new strategy to the synthesis of tashiromine will finally be presented.

Synthesis of Indole Substrate 11. To compare the various nucleophiles we elected to study with the indole ring used in the typical Bischler-Napieralski cyclization, we synthesized the 5-exo cyclization substrate 11 (Scheme 3). Starting from Bocprotected indole, an ortho lithiation and quench with methyl chloroformate gave the indole ester, which was then reduced to the alcohol 9 in $59 \%$ overall yield. Bromination and displacement with the copper enolate of $N, N$-diethylacetamide furnished the amide $10 .{ }^{10} \mathrm{We}$ then pyrolyzed the Boc and methylated the nitrogen to furnish the desired product 11 in $83 \%$ yield. $^{11}$ Although 11 was successfully activated and cyclized (vide infra), an attempted amide activation of $\mathbf{1 0}$ and

(9) Enaminones are particularly interesting and versatile intermediates used for natural product synthesis. See: Michael, J. P.; de Koning, C. B.; Gravestock, D.; Hosken, G. D.; Howard, A. S.; Jungmann, C. M.; Krause, R. W. M.; Parsons, A. S.; Pelly, S. C.; Stanbury, T. V. Pure Appl. Chem. 1999, 71, 979. 
SCHEME 3. Synthesis of the Indole Substrate<smiles>O=C(Oc1ccccc1)n1ccc2ccccc21</smiles>

1) i- $n$-BuLi, THF ii- $\mathrm{ClCO}_{2} \mathrm{Et}$

2) DIBALH, PhH

Boc

$(62 \%)$<smiles>CC(C)(C)OC(=O)n1c(CO)cc2ccccc21</smiles>

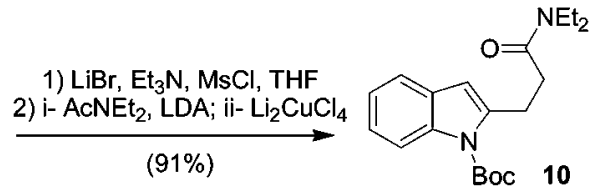

1) $200^{\circ} \mathrm{C}$, neat 2) $\mathrm{Mel}, n-\mathrm{Bu}_{4} \mathrm{NHSO}$ $50 \%$ aq. $\mathrm{NaOH}, \mathrm{PhH}$

$(83 \%)$

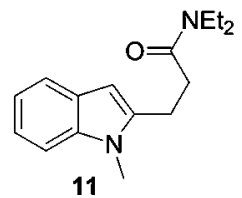

indole trapping of the resulting iminium ion was not productive, presumably because of the poor nucleophilicity of the Bocprotected indole.

Synthesis of 5- and 6-exo Cyclization Substrates. ${ }^{12}$ The chosen 5- and 6-exo cyclization substrates contain either an amide or a lactam as the iminium ion precursor, giving rise to either monocyclic or bicyclic adducts. The synthesis of the secondary amide compound $\mathbf{1 3}$ started with the formation of the silyl enol ether $\mathbf{1 2}$ from the known ethyl 6-oxohexanoate, ${ }^{13}$ using TBDMSOTf (Scheme 4). A DIBALH-benzylamine complex ${ }^{14}$ was then used to convert the ester $\mathbf{1 2}$ to the required secondary amide 13. A series of tertiary amides was also prepared. The enamine $16^{15}$ was formed by the condensation of $N$-methylaniline with the known aldehyde $14,{ }^{16}$ whereas the silyl enol ether 18 was derived from the aldehyde $\mathbf{1 7}$ generated by a Wittig olefination of $\mathbf{1 5}^{8}$ and hydrolysis of the resulting methyl enol ether in $93 \%$ yield for these two steps.

A series of lactams was also prepared, starting with the oxidation of the C-branched $N$-methylpyrrolidinone 19 (Scheme 5). The resulting aldehyde $\mathbf{2 0}$ was then subjected to TBDMSOTf to give the corresponding silyl enol ether 21 , or olefinated ${ }^{17}$ to the allylsilane $\mathbf{2 2}$ in good yields.

Synthesis of 5- and 6-endo Cyclization Substrates. ${ }^{12}$ The preparation of the 5- and 6-endo cyclization substrates containing an amide started with a condensation-reduction sequence

(10) The lithium enolate, from LDA deprotonation of $N, N$-diethylacetamide, gave less than $20 \%$ yield of alkylated product $\mathbf{1 0}$. Addition of lithium chlorocuprate was essential for the success of this reaction. For use of $\mathrm{Li}_{2}$ $\mathrm{CuCl}_{4}$ as catalyst for enolate alkylations, see: Gelin, J.; Mortier, J.; Moyroud, J.; Chene, A. J. Org. Chem. 1993, 58, 3473.

(11) We also tried the same sequence of reactions but starting with $N$-methylindole instead of $N$-Boc-indole. It turns out that the bromo derivative was too unstable and could not be purified before the nucleophilic displacement with the acetamide copper enolate.

(12) The use of exo and endo in this paper refers to the amide portion of the substratres. For a more appropriate description of cationic cyclizations involving -nucleophiles, see: (a) Ben-Ishai, D. J. Chem. Soc., Chem. Commun. 1980, 687. (b) Lochead, A. W.; Proctor, G. R.; Caton, M. P. J. Chem. Soc., Perkin Trans. 1 1984, 2477.

(13) Taber, D. F.; Teng, D. J. Org. Chem. 2002, 67, 1607.

(14) Huang, P.-Q.; Zheng, X.; Deng, X.-M. Tetrahedron Lett. 2001, 42, 9039.

(15) This enamine was unstable, as aldehydic enamines usually are, and had to be used without further purification in the cyclization step. Only the trans enamine was formed.

(16) Cuny, G. D.; Buchwald, S. L. J. Am. Chem. Soc. 1993, 115, 2066.

(17) Fleming, I.; Paterson, I. Synthesis 1979, 446.
SCHEME 4. 5- and 6-exo Cyclization Amide Substrates<smiles>CCOC(=O)CCC/C=C\[C@H](OC(C)C)C(OCC)OCC</smiles>

12
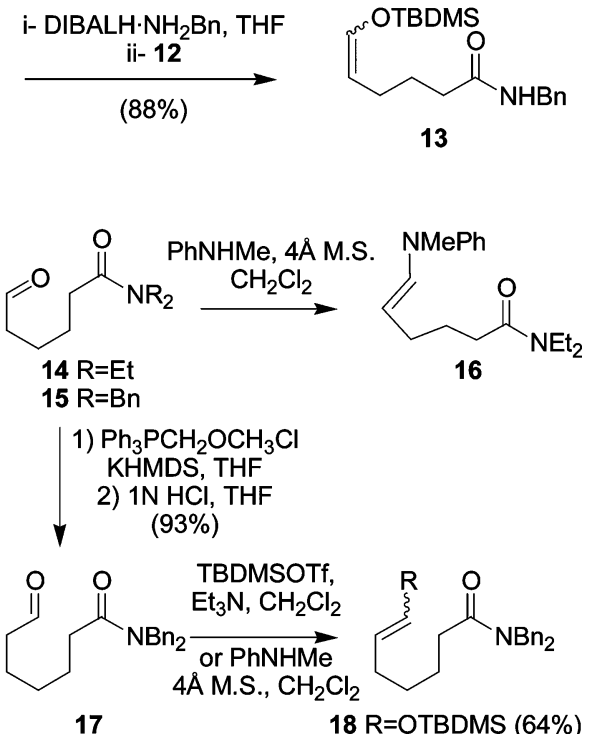

SCHEME 5. 5- and 6-exo Cyclization Lactam Substrates

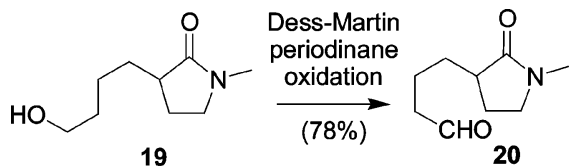

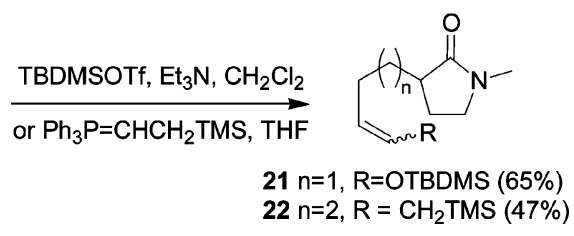

performed on the aldehyde $\mathbf{2 3}^{18}$ to generate the secondary amine 26 (Scheme 6). The four carbon analogue 25 was obtained by the $N$-alkylation of benzylamine with the iodide $24 .{ }^{19}$ A sequence of $N$-acetylation, acidic methanolysis of the silyl ethers 27 and 28, and Swern oxidation furnished the desired aldehydes 29 and 30 respectively in high yields. They were both transformed to the corresponding silyl enol ethers $\mathbf{3 1}$ and $\mathbf{3 2}$ by using either TBDMSOTf with a weak base $\left(\mathrm{Et}_{3} \mathrm{~N}\right)$ or TBDMSCl with a stronger base (KHMDS). Each of these silylation conditions were empirically determined to be the most suitable for these aldehydes.

Finally, we prepared lactams branched on nitrogen with an allylsilane or an enamine as the tethered nucleophiles. The known aldehyde $34^{8}$ was condensed with $N$-methylaniline to give the desired enamine $\mathbf{3 5}$, whereas the aldehyde $\mathbf{3 3}^{8}$ was subjected to the Seyferth-Wittig olefination to furnish the allylsilane $\mathbf{3 6}$ as a 3:1 ratio of geometric isomers (Scheme 7).

(18) Marshall, J. A.; Shearer, B. G.; Crooks, S. L. J. Org. Chem. 1987, $52,1236$.

(19) Fall, Y.; Vidal, B.; Alonso, D.; Gómez, G. Tetrahedron Lett. 2003, 44, 4467.

706 J. Org. Chem., Vol. 71, No. 2, 2006 
TABLE 1. Optimization of the Chemoselective Amide Activation and 5-exo Cyclization with Substrate 37

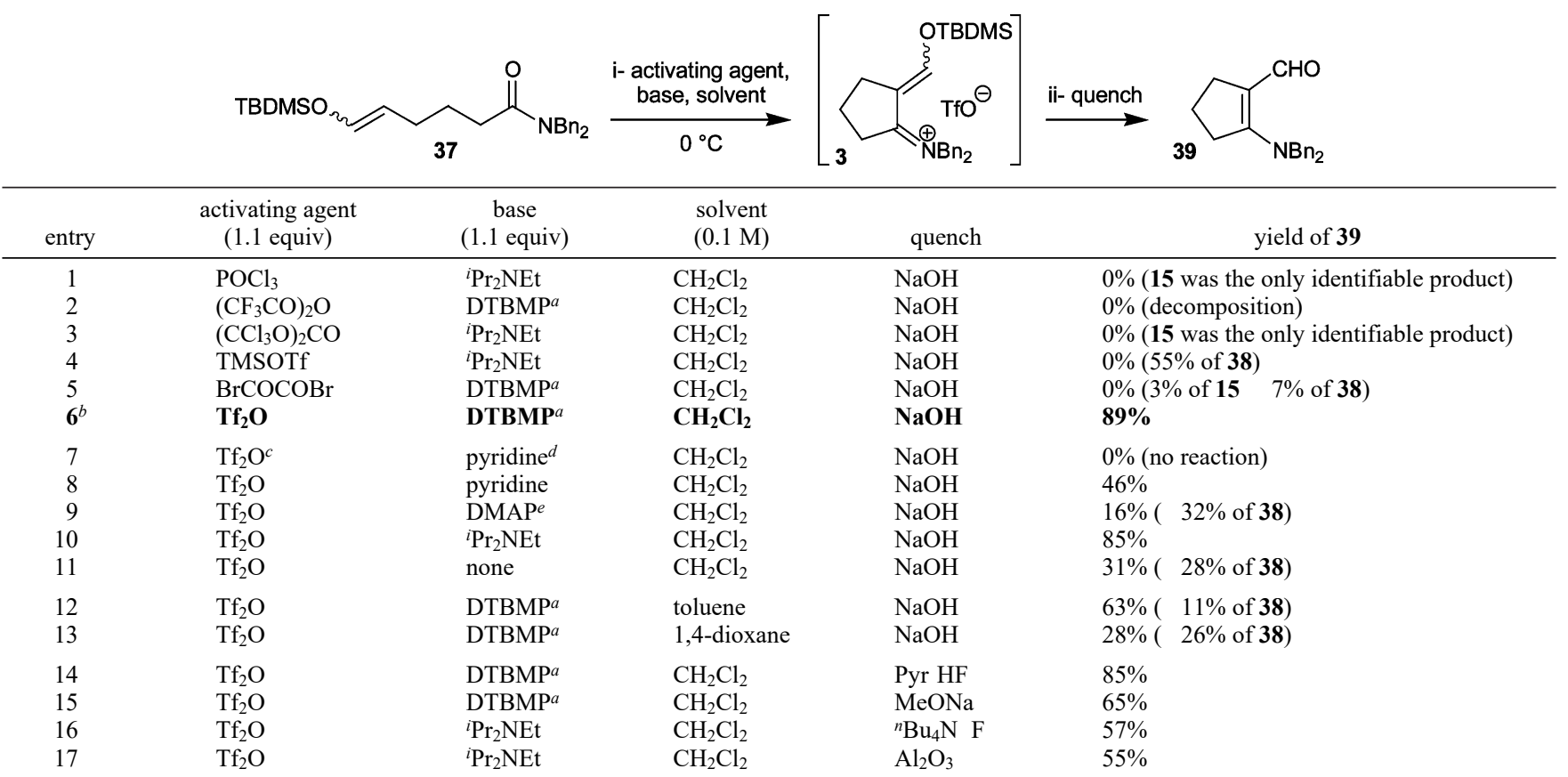

${ }^{a}$ DTBMP: 2,6-di-tert-butyl-4-methylpyridine. ${ }^{b}$ Taken from ref $8 .{ }^{c} 1.3$ equiv, -50 to $0{ }^{\circ} \mathrm{C} .{ }^{d} 1.3$ equiv. ${ }^{e}$ DMAP: 4 -(N,N-dimethylamino)pyridine.

SCHEME 6. 5- and 6-endo Cyclization Amide Substrates
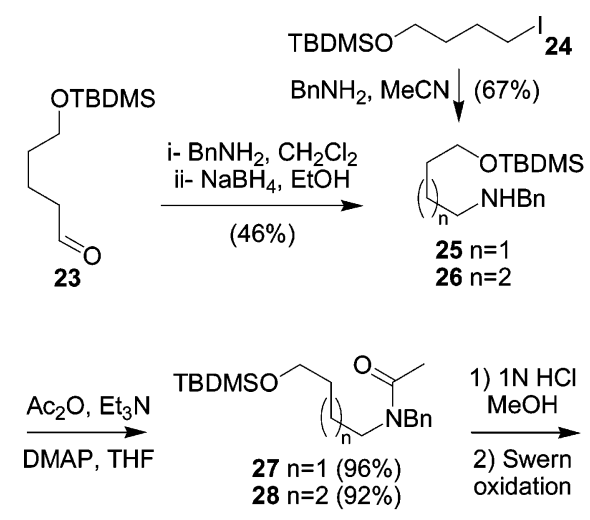

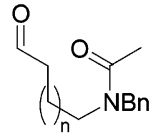

$29 n=1(89 \%)$ $30 \mathrm{n}=2(91 \%)$

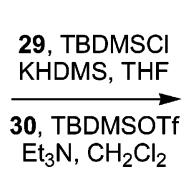

$\mathrm{Et}_{3} \mathrm{~N}, \mathrm{CH}_{2} \mathrm{Cl}_{2}$

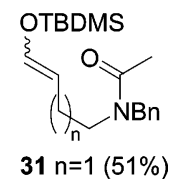

$31 n=1(51 \%)$
$32 n=2(72 \%)$
SCHEME 7. 6-endo Cyclization Lactam Substrates

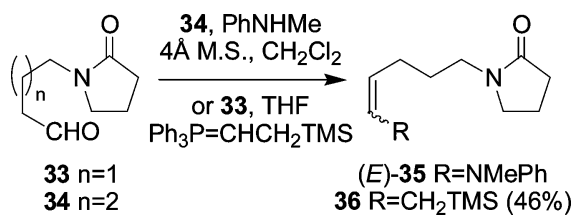

Optimization of the Chemoselective Amide Activation and Cyclization. Four different parameters were studied to set up the most convenient and reproducible reaction conditions for amide activation without altering the tethered nucleophile: (1) the nature of the activating agent, ${ }^{20}(2)$ the need for and the nature of the base, (3) the solvent, and (4) the neutralization (quench) ${ }^{20}$ of the resulting iminium ions (cf. 3, scheme in Table

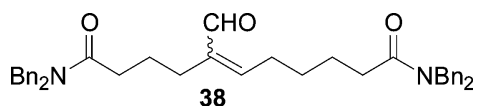

FIGURE 1. Aldol product $\mathbf{3 8}$ from activation of substrate 37 .

1). A study of all of these variables was conducted on the previously reported 5-exo cyclization substrate $37^{8}$ and the results are presented in Table 1.

Many activating agents are known to generate iminium ions from amides. ${ }^{3}$ However, most of them proved to be incompatible with the acid sensitive silyl enol ether present on compound 37. For example, $\mathrm{POCl}_{3}$ (entry 1), TFAA (entry 2), and triphosgene (entry 3) all destroyed the silyl enol ether prior to amide activation, leading to the corresponding aldehyde $\mathbf{1 5}$ or to decomposition. With TMSOTf (entry 4), the silyl enol ether moiety was partially cleaved during the reaction and the aldol product $\mathbf{3 8}$ was obtained in 55\% yield and was fully characterized (Figure 1). The same byproducts (aldehyde 15 and aldol product 38) were obtained in the case of activation with oxalyl bromide, albeit in much lower yields (3\% and 7\%, respectively, entry 5). The best activating agent proved to be $\mathrm{Tf}_{2} \mathrm{O}$ (entry 6 ). The intermediate iminium ion 3 (cf. scheme in Table 1) was characterized by ${ }^{1} \mathrm{H}$ NMR spectroscopy and gave, after a sodium hydroxide hydrolysis, the desired enaminal 39 in $89 \%$ yield (entry 6).

The effect of the base was also surveyed. Excess of pyridine ( 3 equiv) at low temperature $\left(-50 \text { to } 0{ }^{\circ} \mathrm{C} \text {, Table } 2 \text {, entry } 7\right)^{4 \mathrm{c}}$ gave no reaction at all. The same base $\left(1.1\right.$ equiv) used at $0{ }^{\circ} \mathrm{C}$ furnished a $46 \%$ yield of the desired adduct (entry 8 ). This modest yield could arise from a partial reaction of pyridine with $\mathrm{Tf}_{2} \mathrm{O}$ at that temperature, resulting in the formation of $\mathrm{N}$ triflylpyridinium triflate, which is a weaker activating agent than

(20) For this screening, the base used was either 2,6-di-tert-butyl-4methylpyridine or diisopropylethylamine. This is not critical, since entries 6 and 10 of Table 1 gave essentially the same cyclization yield for both of these bases. 
TABLE 2. Cyclization of Indole and Silyl Enol Ethers on Activated Amides and Lactams

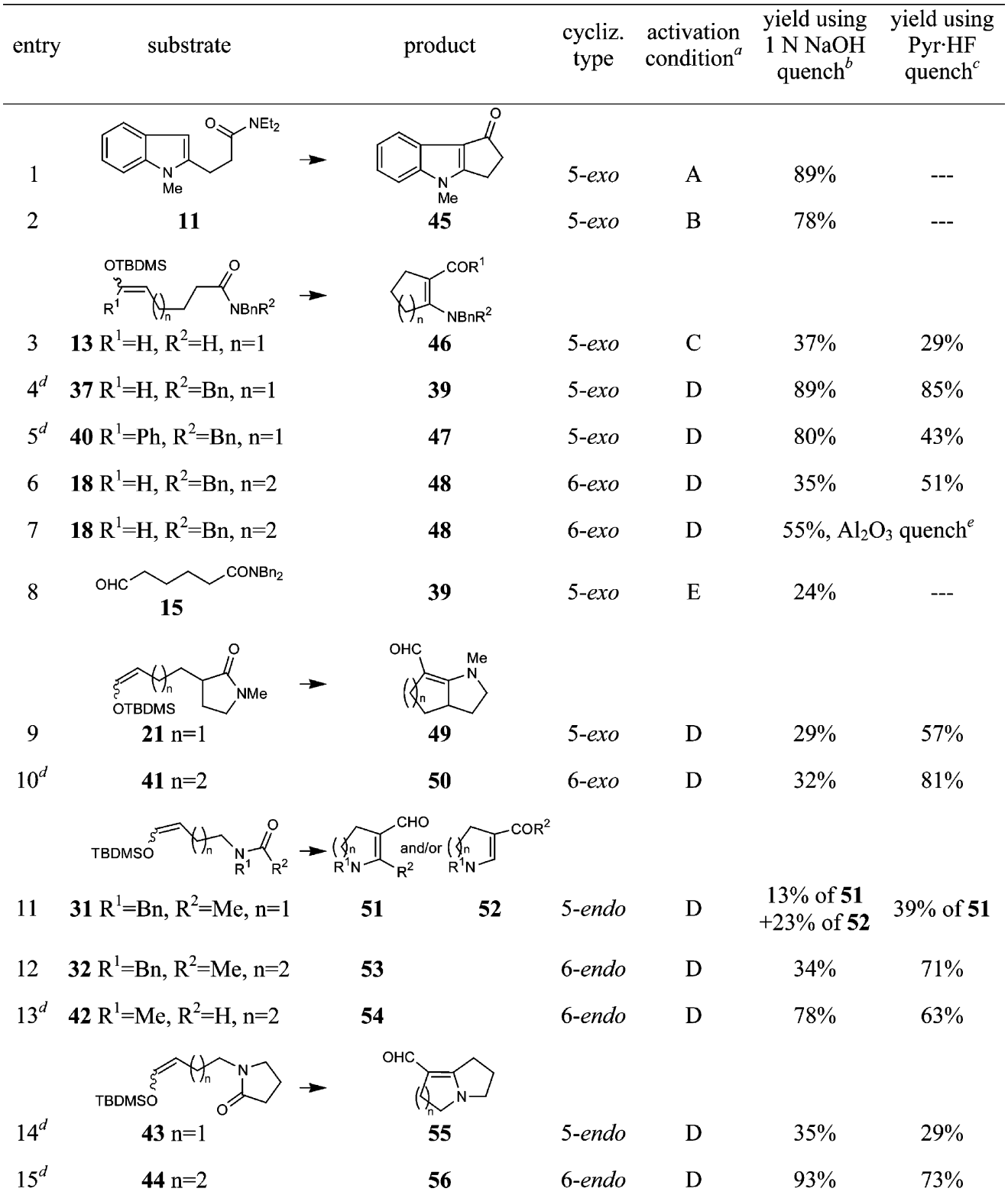

${ }^{a}$ Reagents and conditions: (A) $\mathrm{Tf}_{2} \mathrm{O}$, DMAP, $\mathrm{CH}_{2} \mathrm{Cl}_{2}$, reflux; (B) $\mathrm{POCl}_{3}, \mathrm{ClCH}_{2} \mathrm{CH}_{2} \mathrm{Cl}$, reflux; (C) $\mathrm{Tf}_{2} \mathrm{O}, \mathrm{Pyr}, \mathrm{CH}_{2} \mathrm{Cl}_{2},-50$ to $0^{\circ} \mathrm{C}, 3 \mathrm{~h}$; (D) $\mathrm{Tf}_{2} \mathrm{O}$, 2,6-di-tert-butyl-4-methylpyridine, $\mathrm{CH}_{2} \mathrm{Cl}_{2}, 0^{\circ} \mathrm{C}, 15 \mathrm{~min}$; (E) TMSOTf, ${ }^{i} \mathrm{Pr}_{2} \mathrm{NEt}$; $\mathrm{Tf}_{2} \mathrm{O} .{ }^{b} 1 \mathrm{~N} \mathrm{NaOH}, \mathrm{THF}, 25^{\circ} \mathrm{C}, 15 \mathrm{~h} .{ }^{c} \mathrm{Pyr} \mathrm{HF}, 0{ }^{\circ} \mathrm{C}, 1 \mathrm{~h} .{ }^{d} \mathrm{Taken}$ from ref 8. ${ }^{e}$ Basic $\mathrm{Al}_{2} \mathrm{O}_{3}$, rt, $1 \mathrm{~h}$.

$\mathrm{Tf}_{2} \mathrm{O}$ toward amides. ${ }^{4 \mathrm{c}}$ The same reaction of $\mathrm{Tf}_{2} \mathrm{O}$ with the base was observed when 4 -( $N, N$-dimethylamino)pyridine was used and the even less reactive $N$-triflyl-4-( $N, N$-dimethylamino)pyridinium triflate could account for the poor $16 \%$ yield of entry $9{ }^{21}$ That side reaction was, however, not encountered when Hünig's base (entry 10) or 2,6-di-tert-butyl-4-methylpyridine (entry 6) were used. The latter gave the cleanest conversion and only 1.1 equiv of base was necessary. The reaction was also run in the absence of base (entry 11) and still gave the desired cyclized product 39 without extensive cleavage of the nucleophilic moiety by the triflic acid produced, ${ }^{22}$ but the yield was lower (31\%) and the conversion was less clean.

The solvent also has a significant effect on the yield of the reaction. Dichloromethane was by far the best solvent, giving

(21) A white precipitate is formed in the reaction vessel as soon as $\mathrm{Tf}_{2} \mathrm{O}$ is added to the solution of $\mathbf{3 7}$ and 4 - $(N, N$-dimethylamino)pyridine.

(22) As observed on ${ }^{1} \mathrm{H}$ NMR spectra of aliquots of the reaction. rise to $89 \%$ of the desired enaminal 39 without any formation of the aldol byproduct $\mathbf{3 8}$ (entry 6). Interestingly, the nonpolar solvent toluene still gave a good yield $(63 \%)$ of cyclized product 39, accompanied by $11 \%$ of aldol product 38 (entry 12 ). The proportion of the aldol product was even higher when 1,4dioxane was used, giving an almost 1:1 ratio of enaminal 39 and aldol product 38 (54\% combined yield, entry 13$)$.

Finally, to our surprise, the most crucial parameter to control to get high yields of the desired cyclized product 39 turned out to be the cleavage of the silyl group on the iminium ion intermediate $\mathbf{3}$ in the quench procedure (cf. scheme in Table 1). ${ }^{20}$ Pyr $\mathrm{HF}$ and $\mathrm{NaOH}$ gave very similar results for this substrate (Table 1, 85\% and $89 \%$, entries 14 and 6, respectively), although this was not found to be true for all the cyclized products as will be shown (Tables 2 and 3). With sodium methoxide, a moderate $65 \%$ yield was observed (Table 1 , entry 15). An additional drop in the yield occurred when tetrabutyl- 
TABLE 3. Cyclization of Enamines and Allylsilanes on Activated Amides and Lactams

entry

${ }^{a}$ Reagents and conditions: (A) $\mathrm{Tf}_{2} \mathrm{O}, \mathrm{CH}_{2} \mathrm{Cl}_{2}, 0^{\circ} \mathrm{C}, 20 \mathrm{~min}$; (B) $\mathrm{Tf}_{2} \mathrm{O}, 2$,6-di-tert-butyl-4-methylpyridine, $\mathrm{CH}_{2} \mathrm{Cl}_{2}, 0^{\circ} \mathrm{C}, 15$ min. ${ }^{b}$ Taken from ref 8 . ${ }^{c}$ Concentrated then purified directly. ${ }^{d} \mathrm{NaBH}_{3} \mathrm{CN},-78$ to $0{ }^{\circ} \mathrm{C}, 15$ h. ${ }^{e} 15$ h. ${ }^{f} \mathrm{ClCH}_{2} \mathrm{CH}_{2} \mathrm{Cl}$, reflux, $15 \mathrm{~h}$.

ammonium fluoride (57\% yield, entry 16$)$ or basic alumina $(55 \%$ yield, entry 17) was used. We do not fully understand the large influence of the quench reagents on the reaction yield, but a possible explanation could be the ease with which highly water soluble hydrates form in certain quench conditions, as will be discussed below.

5-exo, 6-exo, 5-endo, and 6-endo Cyclizations of Various Tethered Nucleophiles on Amides and Lactams. The optimized cyclization conditions were applied to the cyclization of other 5-exo cyclization substrates, as well as to 6-exo, 5-endo, and 6-endo cyclization substrates (Tables 2 and 3). In the case of substrates containing a silyl enol ether branch (Table 2), Pyr $\mathrm{HF}$ and $\mathrm{NaOH}$ were systematically used to cleave the silyl group on the iminium ion intermediate in the quench procedure (cf. 3, scheme in Table 1), whereas other quench procedures specifically noted were used in the cases of substrates tethered to an enamine or an allylsilane (Table 3).

Comparison of the Cyclization Types (5- or 6-, exo or endo). A comparison could be made over four cyclization types only with silyl enol ether nucleophiles, tethered to aliphatic amides or to lactams (Table 2). For comparison purposes, we looked at the yields obtained with the Pyr HF quench. Only in the case of the activation of aliphatic amides and cyclization did the yields indicate that the 5-exo mode is by far the best $(85 \%$, entry 4$)$, followed by the 6 -endo $(71 \%$, entry 12$)$, the 6 -exo (51\%, entry 6), and the 5-endo (39\%, entry 11$)$ modes. This order was somewhat different with lactams: the 6-exo mode is the best ( $81 \%$, entry 10$)$, followed by the 6 -endo $(73 \%$, entry 15$)$, the 5 -exo $(57 \%$, entry 9$)$, and the 5-endo (29\%, entry 14) modes.

However, the yields obtained with the $\mathrm{NaOH}$ cleavage of the silyl group on the iminium ion intermediate in the quench

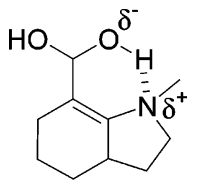

FIGURE 2. Proposed water soluble carbonyl hydrate of $\mathbf{5 0 .}$

procedure (cf. 3, scheme in Table 1) show significant variations. The most remarkable example is with the 6-exo cyclization substrate 41 (entry 10, Table 2). Although the cyclization was always complete and very clean, as indicated by the analysis of ${ }^{1} \mathrm{H}$ NMR spectra of reaction aliquots, the hydrolysis step was particularly problematic. In fact, the bicyclic enaminal $\mathbf{5 0}$ was obtained in a much lower yield with a $\mathrm{NaOH}$ quench $(32 \%)$ than with a Pyr HF quench (81\%). Intrigued by that result, we stirred pure 6-exo cyclization product $\mathbf{5 0}$ in a $1: 1$ mixture of THF and water for $15 \mathrm{~h}$ and observed a complete loss of the product (the yield dropped to $0 \%$ ). Evaporation of the aqueous phase led to various unidentifiable products. We suggest that a polar, water soluble carbonyl hydrate with strong hydrogen bonding might be responsible for the loss of material (Figure 2 ). The formation of a stable hydrate may also account for the difference in yields of the 6-exo cyclization of silyl enol ether substrate 18. Again, the Pyr HF quench was superior to the $\mathrm{NaOH}$ quench $(51 \%$ and $35 \%$ yield, respectively, entry 6 , Table 2 ), although a basic alumina quench was even better (55\% yield, entry 7). Such hydrogen bond stabilized hydrates are impossible for the endo cyclization products with allylsilanes or enamines (cf. Table 3, entries 6 and 3, respectively).

Although this explains well the difference in yields of the two quench procedures applied to the same products for the 
SCHEME 8. Proposed Mechanism for the Rearrangement of 51 to 52 in $1 \mathrm{~N} \mathrm{NaOH}$

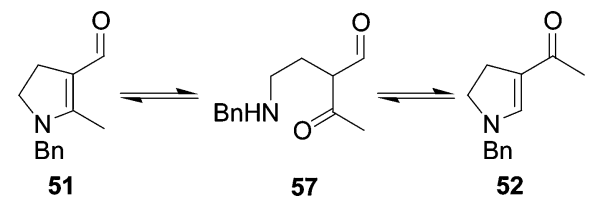

cleavage of the silyl group on the iminium ion intermediate, it does not explain all of the differences observed. For example, while enaminal $\mathbf{5 1}$ was the only product formed when the Pyr HF quench was used, a rearranged product $\mathbf{5 2}$ appeared with the $\mathrm{NaOH}$ quench (entry 11, Table 2). In theory, the enaminal 51 should be the only product of a direct cyclization of the silyl enol ether moiety onto the activated amide of $\mathbf{3 1}$. We suggest that compound $\mathbf{5 1}$ arises from the 1,4-addition of hydroxide anion to the enal of $\mathbf{5 2}$, followed by the ring opening to the amino -keto aldehyde 57, and condensation of the amine with the aldehyde (Scheme 8). This hypothesis was confirmed: mixtures of compounds $\mathbf{5 1}$ and $\mathbf{5 2}$ were observed when both $\mathbf{5 1}$ and $\mathbf{5 2}$ were treated independently with $1 \mathrm{~N} \mathrm{NaOH}$.

The hydrolysis problems were not encountered in the case of the enamines and the allylsilanes we cyclized (Table 3) and should allow for a more accurate comparison between the cyclization modes. However, the yields given for the enamines include their in situ preparation from the corresponding aldehydes, which are not uniform over the different substrates. Thus, we could not draw any precise conclusion about the ease of cyclization of enamines for the different modes of cyclization. In the case of the activation and cyclization of lactams tethered to allylsilanes, the 6-exo mode (93\% yield, entry 5) proved to be more efficient than the 6-endo mode (70\% yield, entry 6), following the trend observed with the silyl enol ethers (entries 10 and 15, Table 2, with the Pyr HF quench). Although the cyclizations of silyl enol ether onto aliphatic amides or lactams were all completed within $15 \mathrm{~min}$, cyclizations of allylsilanes onto activated lactams were much slower $(15 \mathrm{~h})$ than on the activated amide (15 min). This is probably due to a higher steric congestion of lactams (additional substitution $\alpha$ to lactam carbonyl) compared to the aliphatic amide and a lower reactivity of the allylsilane compared to the TBDMS enol ether, resulting in a higher sensitivity of the allylsilane to steric hindrance (earlier transition state with TBDMS enol ether than with allylsilane).

Comparison of the Nucleophiles. A series of tethered nucleophiles were screened with use of substrates that cyclized by the same mode (5/6-endo/exo) and having the same amide or lactam. All enolizable carbonyl groups (ketones and -ketoesters, not tabulated) we tested proved to be incompatible with the amide activation conditions: either the enol tautomer was more reactive than the amide toward the activating agent, or the activated amide could not be trapped with the enolized carbonyl. ${ }^{23}$ We obtained the best results with silyl enol ethers, enamines, and allylsilanes, as shown in Tables 2 and 3. For the 5-exo cyclizations, the silyl enol ether $\mathbf{3 7}$ gave the highest yield (89\%, entry 4, Table 2), followed by the allylsilane $59(81 \%$, entry 4, Table 3 ) and the enamine 58 (74\%, entry 1, Table 3). This order was somewhat different with 6-endo cyclizations of lactams 44 (silyl enol ether, 93\%, entry 15, Table 2), 35 (enamine, $78 \%$, entry 3 , Table 3 ), and $\mathbf{3 6}$ (allylsilane, $70 \%$, entry 6 , Table 3 ) or with 6-exo cyclizations of lactams 22 (allylsilane,

(23) Nantel, M. M.Sc. Thesis, Université de Sherbrooke, 2004, 183 pages.
93\%, entry 5, Table 3) and $\mathbf{4 1}$ (silyl enol ether, 81\%, entry 10, Table 2). Intriguingly, this order does not reflect the -nucleophilicity tabulated by Mayr, ${ }^{24}$ which places enamines on top of the list, followed by silyl enol ethers then allylsilanes. Because we could not report yields for the cyclization step only, ${ }^{25}$ we cannot make a precise correlation between the -nucleophilicity of the tethered nucleophiles used and the yields of cyclized products.

As enamines were prepared from the corresponding aldehydes and cyclized one-pot, we wanted to see if the same could be done with silyl enol ethers. In entry 8 of Table 2, the aldehyde $\mathbf{1 5}$ was silylated with TMSOTf in the presence of a base, then $\mathrm{Tf}_{2} \mathrm{O}$ was added to the reaction mixture without isolation of the silyl enol ether intermediate. After hydrolysis, the enaminal 39 was isolated in $24 \%$ yield $(\mathrm{NaOH}$ quench), compared to a $53 \%$ overall yield for the stepwise silylation $(60 \%$ yield, ref 8$)$ and cyclization ( $89 \%$ yield, entry 4 , Table 2$)$. There is thus an obvious advantage of preparing the silyl enol ether in a separate operation, before the cyclization. Looking at the result obtained from the one-pot preparation and cyclization of enamine $\mathbf{5 8}$ (entry 1, Table 3), it seems that the enamine formation is much more compatible with the following one-pot activationcyclization step than is the silyl enol ether formation.

After a Pyr HF quench, the ketonic silyl enol ether $\mathbf{4 0}$ cyclized in about half the yield of that obtained with the corresponding aldehydic silyl enol ether 37 (Table 2, entries 5 and 4, 43\% and $85 \%$ yield, respectively), although this difference was less important when a $\mathrm{NaOH}$ quench was used $(80 \%$ and $89 \%$ yield, respectively). These results indicate a small influence of the substitution of the silyl enol ether on the cyclization, but a greater influence on the procedure used to cleave the TBDMS group on the iminium ion intermediate (such as $\mathbf{3}$, Scheme 2).

The indole 11 (entry 1, Table 2) and the nonaromatic enamine 16 (entry 2, Table 3) cyclized in $89 \%$ and $78 \%$ yield, respectively. The amide activation and cyclization requires heating at $40{ }^{\circ} \mathrm{C}$ during several hours for the indole 11, compared to enamine 16, which cyclized within $15 \mathrm{~min}$ at 0 ${ }^{\circ} \mathrm{C}$. Because the only difference between these substrates is the nature of the tethered nucleophile, the difference in the reaction temperatures and time is indicative of the greater reactivity of aliphatic enamine relative the indole ring toward activated amide. It should be noted that activation of the indole tethered amide 11 with $\mathrm{POCl}_{3}$ (entry 2, Table 2) was less efficient than the activation with $\mathrm{Tf}_{2} \mathrm{O}$ (entry 1), as was observed for compound 37 (Table 1 , entries 1 and 6). ${ }^{26}$

Comparison between Amides and Lactams. We compared the cyclization of identical nucleophilic moieties tethered to either aliphatic amides or butyrolactams. For the 5-exo cyclization of silyl enol ethers (entries 4 and 9, Table 2), the yield is much higher with the aliphatic amide $(85-89 \%)$ than with the lactam $(29-57 \%)$, whereas this order is reversed for the 6-exo

(24) Mayr, H.; Kempf, B.; Ofial, A. R. Acc. Chem. Res. 2003, 36, 66 (25) (a) For allylsilanes, the yields are reported for their cyclization and reduction. Attempts to hydrolyze the , -unsaturated iminium ion (such as 5, Scheme 1) after cyclization gave inseparable mixtures of $\alpha$, - and , enones. The reduction of the same iminium was also a lot cleaner than the hydrolysis. (b) For silyl enol ethers, the yields are reported for their cyclization and hydrolysis. (c) For aldehydic enamines, which are unstable and could not be isolated, the yields are reported for their formation and cyclization. Hydrolysis of the resulting vinylogous amidinium ions (such as $\mathbf{4}$, Scheme 2) was not necessary because they were easily isolated and characterized.

(26) The intermediate vinylogous amidinium ion was characterized by ${ }^{1} \mathrm{H}$ NMR spectroscopy prior to hydrolysis (see the Supporting Information). 
(entries 6 and 10, respectively) and the 6-endo cyclizations (entries 12 and 15). For both amides and lactams, as expected, 5 -endo cyclizations are difficult but possible (39\% and $29 \%$ yield, entries 11 and 14, respectively), showing the high reactivity of activated amides toward the -nucleophiles we used.

We also demonstrated that a tertiary amide (entry 4, Table 2) gives a much higher yield of enaminal than does a secondary amide (entry 3). The latter was not as easy to activate cleanly, and the nucleophilic addition of silyl enol ether was not as efficient. The activated secondary amide being a neutral imidate, it was anticipated that this imidate would be less reactive that the parent iminium ion from activation of tertiary amide. ${ }^{27}$ When we compared the formamide 42 (entry 13, Table 2) to the corresponding acetamide 32 (entry 12) and lactam 44 (entry $15)$, the resulting enaminals $\mathbf{5 4}, \mathbf{5 3}$, and $\mathbf{5 6}$ respectively were obtained in similar yields $(63 \%, 71 \%$, and $73 \%$, respectively) with the Pyr HF quench. This suggests a low influence of the iminium congestion in the cyclization step. However, when looking at the same entries but with the $\mathrm{NaOH}$ quench, there are large variations in the isolated yields (78\% of $54,34 \%$ of 53, and $93 \%$ of 56). The ease of hydrolysis may explain the better yield for the formation of adduct 54 (78\%, entry 13$)$ over 53 (34\%, entry 12), but we do not have a clear explanation for the high yield of 56 (93\%). Finally, when we compare $N, N$ dibenzylamide 58 (74\% yield, entry 1, Table 3) with $N, N$ diethylamide 16 (78\% yield, entry 2$)$, the nature of the alkyls on the amide nitrogen does not seem to have a large influence on the cyclization yield.

Application to the Synthesis of $( \pm)$-Tashiromine. Tashiromine (66) is an indolizidine alkaloid isolated in 1990 from the stems of a leguminous plant Maackia tashiroi, a deciduous shrub of subtropical Asia. ${ }^{28}$ Six syntheses have been reported to date. ${ }^{29}$ In our synthesis, we make use of the 6-endo cyclization of a TBDMS enol ether onto the activated butyrolactam $44^{8}$ to generate the bicyclic core of $( \pm)$-tashiromine in $93 \%$ yield. Upon treatment of the enaminal 56 with $\mathrm{H}_{2}$ and $\mathrm{Pd}$ on carbon in the presence of $\mathrm{Na}_{2} \mathrm{CO}_{3},{ }^{30}$ a 20:1 mixture of $( \pm)$-tashiromine (66) and $( \pm$ )-epitashiromine was obtained in $73 \%$ yield (or $79 \%$ yield, based on recovered starting material, Scheme 9). Because the syn-addition of hydrogen to the enaminal $\mathbf{5 6}$ alkene should lead to $( \pm)$-epitashiromine, we think that once the alkene in $\mathbf{5 6}$ is hydrogenated, a $\mathrm{Na}_{2} \mathrm{CO}_{3}$ catalyzed epimerization $\alpha$ to the remaining aldehyde is faster than the hydrogenation of that aldehyde. The epimerization prior to the aldehyde reduction places the formyl group in the thermodynamic equatorial orientation. The synthesis of $( \pm)$-tashiromine was thus accomplished in 6 steps with an overall yield of $26 \%$, which compares favorably to previously reported syntheses. ${ }^{29}$ This expeditious synthesis is a prelude to the potential of amide activation and nucleophilic cyclization for the total synthesis of alkaloids.

(27) Charette, A. B.; Chua, C. Tetrahedron Lett. 1998, 39, 245.

(28) Ohmiya, S.; Kubo, H.; Otomasu, H.; Saito, K.; Murakoshi, I. Heterocycles 1990, 30, 537.

(29) (a) Nagao, Y.; Dai, W.-M.; Ochiai, M.; Tsukagoshi, S.; Fujita, E. J. Org. Chem. 1990, 55, 1148. (b) Paulvannan, K.; Stille, J. R. J. Org. Chem. 1994, 59, 1613. (c) Gage, J. L.; Branchaud, B. P. Tetrahedron Lett. 1997, 38, 7007. (d) David, O.; Blot, J.; Bellec, C.; Fargeau-Bellassoued, M.-C.; Haviari, G.; Célérier, J.-P.; Lhommet, G.; Gramain, J.-C.; Gardette, D. J. Org. Chem. 1999, 64, 3122. (e) Kim, S.-H.; Kim, S.-I.; Lai, S.; Cha, J. K. J. Org. Chem. 1999, 64, 6771. (f) Banwell, M. G.; Beck, D. A. S.; Smith, J. A. Org. Biomol. Chem. 2004, 2, 157.

(30) Paulvannan, K.; Schwarz, J. B.; Stille, J. R. Tetrahedron Lett. 1993, $34,215$.
SCHEME 9. Synthesis of $( \pm)$-Tashiromine
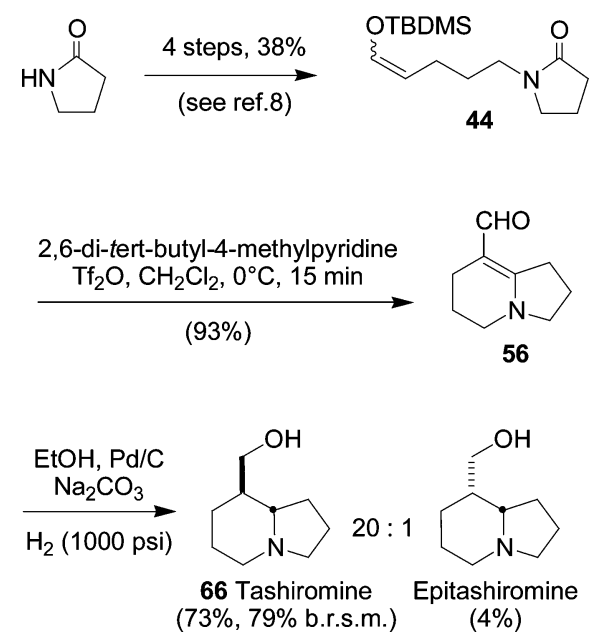

\section{Conclusions}

We demonstrated for the first time that activated amides could be trapped with tethered nonaromatic carbon nucleophiles in good to excellent yields. We showed that silyl enol ethers, enamines, and allylsilanes are compatible with amide activation and are the most efficient and well-suited nucleophiles for adding to the resulting iminium ion. Tashiromine is an example of the alkaloids that are accessible by the new monocyclizations we developed. We also confirmed that the species in solution after cyclization are iminium ions, whatever nucleophile is used for the cyclization. This is highly encouraging for the pursuit of our work toward our planned bis-cyclization strategy. The latter will furthermore open applications to the synthesis of polycyclic alkaloids. The results will be reported in due course.

\section{Experimental Section}

4-Methyl-3,4-dihydro-2H-cyclopenta $[b]$ indol-1-one (45). Activation with $\mathbf{P O C l}_{3}$ : To a solution of the amide $\mathbf{1 1}$ (100 mg, 0.390 $\mathrm{mmol})$ in toluene $(3.9 \mathrm{~mL})$ at room temperature was added $\mathrm{POCl}_{3}$ (43 L, $0.46 \mathrm{mmol}$ ). The mixture was then heated to reflux and kept at that temperature overnight. The dark mixture was cooled to room temperature and the solvent was evaporated under reduced pressure to yield the iminium chloride salt intermediate as a solid: ${ }^{1} \mathrm{H}$ NMR (300 MHz, $\left.\mathrm{CDCl}_{3}\right) \quad 7.63(\mathrm{~d}, J=7.5 \mathrm{~Hz}, 1 \mathrm{H}), 7.28(\mathrm{~d}$, $J=7.5 \mathrm{~Hz}, 1 \mathrm{H}), 7.16(\mathrm{t}, J=7.5 \mathrm{~Hz}, 1 \mathrm{H}), 7.07(\mathrm{t}, J=7.5 \mathrm{~Hz}$, $1 \mathrm{H}), 4.14(\mathrm{q}, J=7.5 \mathrm{~Hz}, 2 \mathrm{H}), 3.89-3.82(\mathrm{~m}, 5 \mathrm{H}), 3.73-3.72(\mathrm{~m}$, $2 \mathrm{H}), 3.43-3.40(\mathrm{~m}, 2 \mathrm{H}), 1.58(\mathrm{t}, J=7.5 \mathrm{~Hz}, 3 \mathrm{H}), 1.49(\mathrm{t}, J=7.5$ $\mathrm{Hz}, 3 \mathrm{H}) ; \mathrm{MS}(\mathrm{m} / \mathrm{z}) 240\left(\mathrm{M}^{+}\right)$. The crude iminium salt was dissolved in a 1:1 solution of THF $(2 \mathrm{~mL})$ and $3 \mathrm{~N} \mathrm{NaOH}(2 \mathrm{~mL})$ and allowed to stir at room temperature overnight. After hydrolysis, most of the THF was removed by evaporation under reduced pressure. The resulting aqueous phase was extracted three times with $\mathrm{CH}_{2} \mathrm{Cl}_{2}$. The combined organic phases were dried with anhydrous sodium sulfate, filtered, and evaporated under reduced pressure. The crude product was purified by flash chromatography (silica gel, 2:98 $\mathrm{MeOH}-\mathrm{EtOAc})$ to give $60 \mathrm{mg}(78 \%)$ of pure 45 as a solid. Activation with $\mathbf{T f}_{\mathbf{2}} \mathbf{O}$ : To a solution of the amide $\mathbf{1 1}(100 \mathrm{mg}$, $0.390 \mathrm{mmol})$ in dichloromethane $(3.9 \mathrm{~mL})$ at room temperature was added 4-( $N, N$-dimethylamino)pyridine (47 mg, $0.39 \mathrm{mmol})$, followed by $\mathrm{Tf}_{2} \mathrm{O}(130 \mathrm{~L}, 770 \mathrm{~mol})$. The solution was stirred at room temperature for $2 \mathrm{~h}$, then was heated to reflux overnight. The reaction was worked up and purified as described in the $\mathrm{POCl}_{3}$ activation method (vide supra) to give $64 \mathrm{mg}(89 \%)$ of pure $\mathbf{4 5}$ as a solid. ${ }^{31}$ 
1,2,3,5,6,7-Hexahydroindolizine-8-carbaldehyde (56). $\mathrm{Tf}_{2} \mathrm{O}(33$ $\mu \mathrm{L}, 0.19 \mathrm{mmol}$ ) was added dropwise to a solution of $44^{8}(50 \mathrm{mg}$, $0.18 \mathrm{mmol}$ ) and 2,6-di-tert-butyl-4-methylpyridine $(40 \mathrm{mg}, 0.19$ mmol) in $\mathrm{CH}_{2} \mathrm{Cl}_{2}(2 \mathrm{~mL})$ at $0{ }^{\circ} \mathrm{C}$, then the reaction mixture was stirred at $0{ }^{\circ} \mathrm{C}$ during $20 \mathrm{~min}$. Pyr $\cdot \mathbf{H F}$ quench: a prepared solution of Pyr $\cdot \mathrm{HF} /$ pyridine/THF $(4: 5: 20,0.11 \mathrm{~mL})$ was added dropwise at $0{ }^{\circ} \mathrm{C}$, and the reaction mixture was stirred at $0{ }^{\circ} \mathrm{C}$ for $20 \mathrm{~min}$. $\mathrm{NaOH}$ $(1 \mathrm{~N})$ was added, layers were separated, and the aq phase was extracted with $\mathrm{CH}_{2} \mathrm{Cl}_{2}$. Organic phases were combined, dried over anhyd $\mathrm{Na}_{2} \mathrm{SO}_{4}$, filtered, and concentrated under reduced pressure. The crude material was purified by flash chromatography (basic alumina, 100:2 EtOAc-MeOH) to give pure 56 as a yellowish oil. NaOH quench: the reaction mixture was concentrated by using a nitrogen flow, then THF $(2 \mathrm{~mL})$ and $1 \mathrm{~N} \mathrm{NaOH}(2 \mathrm{~mL})$ were added and the mixture was vigorously stirred overnight at room temperature. THF was evaporated under reduced pressure and the aq phase was extracted with $\mathrm{CH}_{2} \mathrm{Cl}_{2}$. The combined organic phases were dried over anhyd $\mathrm{Na}_{2} \mathrm{SO}_{4}$, filtered, and concentrated under reduced pressure. The crude material was purified by flash chromatography (basic alumina, 100:2 EtOAc-MeOH) to give $25 \mathrm{mg}$ (93\%) of pure 56 as a yellowish oil: ${ }^{1} \mathrm{H}$ NMR $\left(300 \mathrm{MHz}, \mathrm{CDCl}_{3}\right) \delta 9.22(\mathrm{~s}, 1 \mathrm{H})$, 3.45 (t, $J=7.0 \mathrm{~Hz}, 2 \mathrm{H}), 3.26(\mathrm{t}, J=5.5 \mathrm{~Hz}, 2 \mathrm{H}), 2.99$ (t, $J=7.0$ $\mathrm{Hz}, 2 \mathrm{H}), 2.33$ (t, $J=5.5 \mathrm{~Hz}, 2 \mathrm{H}$ ), 2.05 (qi, $J=7.0 \mathrm{~Hz}, 2 \mathrm{H}), 1.83$ (qi, $J=5.5 \mathrm{~Hz}, 2 \mathrm{H}) ;{ }^{13} \mathrm{C} \mathrm{NMR}\left(75 \mathrm{MHz}, \mathrm{CDCl}_{3}\right) \delta 183.0,164.4$, 103.6, 53.4, 45.2, 28.5, 20.8, 20.6, 17.7; IR (film) $v$ 2939, 1577, 1438, $1108 \mathrm{~cm}^{-1}$; HRMS (EI) calcd for $\mathrm{C}_{9} \mathrm{H}_{13} \mathrm{NO}\left(\mathrm{M}^{+}\right)$151.0997, found 151.0994 .

(E)- $N, N$-Dibenzyl- $N$-[2-( $N^{\prime}$-methyl- $N^{\prime}$-phenylaminomethylene)cyclopentylidene]ammonium Trifluoromethanesulfonate (60). Molecular sieves ( $4 \AA, 600 \mathrm{mg}$ ) were added to a solution of $\mathbf{1 5}^{8}$ (200 mg, $0.647 \mathrm{mmol})$ in $\mathrm{CHCl}_{3}(5.0 \mathrm{~mL})$ at $20^{\circ} \mathrm{C}$. $N$-Methylaniline $(0.17 \mathrm{~mL}, 1.6 \mathrm{mmol})$ was added and the reaction mixture was stirred for $24 \mathrm{~h}$ at room temperature. Conversion of $\mathbf{1 5}$ to the enamine $\mathbf{5 8}$ was followed by ${ }^{1} \mathrm{H}$ NMR of $0.1 \mathrm{~mL}$ aliquots sampled from the heterogeneous reaction mixture and diluted with $\mathrm{CDCl}_{3}$ in an NMR tube. ${ }^{32}$ The reaction mixture was cooled to $0{ }^{\circ} \mathrm{C}$, then ${ }^{i} \mathrm{Pr}_{2} \mathrm{NEt}$ was added $(0.32 \mathrm{~mL}, 1.86 \mathrm{mmol})$, followed by a dropwise addition of $\mathrm{Tf}_{2} \mathrm{O}(0.29 \mathrm{~mL}, 1.86 \mathrm{mmol})$ over $15-20 \mathrm{~min}$. The reaction mixture was stirred for $15 \mathrm{~min}$ at $0{ }^{\circ} \mathrm{C}$, then allowed to warm to room temperature and filtered on Celite $\left(\mathrm{CH}_{2} \mathrm{Cl}_{2}\right.$ washing). The clear orange filtrate was concentrated under reduced pressure and the residue was purified by flash chromatography (silica gel, 2:5:100 $\mathrm{AcOH}-\mathrm{MeOH}-\mathrm{CH}_{2} \mathrm{Cl}_{2}$ ) affording $254 \mathrm{mg}(74 \%)$ of pure 60 as an amorphous semisolid: ${ }^{1} \mathrm{H}$ NMR $\left(300 \mathrm{MHz}, \mathrm{DMSO}-d_{6}\right) \delta 7.79$ (s, 1H), 7.48-6.97 (m, 15H), 5.10 (br s, 4H), 4.48 (br s, 3H), 3.45 (s, 2H), 2.99 (t, $J=7.5 \mathrm{~Hz}, 2 \mathrm{H}), 1.70$ (br s, 2H); ${ }^{13} \mathrm{C}$ NMR $(75$

(31) The characterization is identical with the one reported for the same compound, but prepared through another route. See: (a) Bergman, J.; Baeckvall, J. E. Tetrahedron 1975, 31, 2063. (b) Gardette, D.; Gramain, J. C.; Lepage, M. E.; Troin, Y. Can. J. Chem. 1989, 67, 213.

(32) Ratios were determined from the characteristic signal for the protons $\alpha$ to the amide carbonyl of $\mathbf{1 4}$ and 58 appearing at $2.18 \mathrm{ppm}(4 \mathrm{H})$ versus the overlapping multiplets at $1.7-1.6 \mathrm{ppm}$ accounting for a total of $6 \mathrm{H}$ (4H, $\beta$ and $\gamma$ to the amide carbonyl, in 15 , and $2 \mathrm{H} \beta$ to the amide carbonyl in 58).
MHz, DMSO- $\left.d_{6}\right) \delta 186.3,158.6,148.8,140.0,135.2,133.9,133.2$, 132.4, 132.0, 128.7, 110.3, 65.3, 55.4, 41.2, 36.6, 26.3; IR (film) $v$ 3032, 2950, 2867,1608,1541,1495,1262,1149, $1031 \mathrm{~cm}^{-1}$; HRMS (EI) calcd for $\mathrm{C}_{27} \mathrm{H}_{28} \mathrm{~N}_{2}{ }^{+}\left(\mathrm{M}^{+}\right) 380.2252$, found 380.2246 .

8-Ethylidene-2,3,5,6,7,8-hexahydro- $1 \mathrm{H}$-indolizinylium Trifluoromethanesulfonate (65). $\mathrm{Tf}_{2} \mathrm{O}(77 \mu \mathrm{L}, 0.46 \mathrm{mmol})$ was added dropwise to a solution of $36(100 \mathrm{mg}, 0.42 \mathrm{mmol})$ and 2,6-di-tertbutyl-4-methylpyridine ( $95 \mathrm{mg}, 0.46 \mathrm{mmol}$ ) in $\mathrm{CH}_{2} \mathrm{Cl}_{2}(4 \mathrm{~mL})$ at 0 ${ }^{\circ} \mathrm{C}$. After $20 \mathrm{~min}$ at $0{ }^{\circ} \mathrm{C}$, the resulting mixture was allowed to warm to room temperature over $2 \mathrm{~h}$, stirred overnight, then concentrated. 1,2-Dichloroethane $(4 \mathrm{~mL})$ was added and the solution was heated to reflux for $15 \mathrm{~h}$, then was allowed to cool to room temperature and concentrated. The crude material was purified by flash chromatography (silica gel, 2:5:100 AcOH- $\mathrm{MeOH}-\mathrm{CH}_{2} \mathrm{Cl}_{2}$ ) to afford $88 \mathrm{mg}(70 \%)$ of pure 65 as a yellowish semisolid: ${ }^{1} \mathrm{H}$ $\operatorname{NMR}\left(300 \mathrm{MHz}, \mathrm{CDCl}_{3}\right) \delta 6.93(\mathrm{q}, J=7.0 \mathrm{~Hz}, 1 \mathrm{H}), 4.28(\mathrm{t}, J=$ $7.5 \mathrm{~Hz}, 2 \mathrm{H}), 3.81$ (br t, $J=6.0 \mathrm{~Hz}, 2 \mathrm{H}), 3.37$ (t, $J=7.5 \mathrm{~Hz}, 2 \mathrm{H}$ ), $2.57(\mathrm{t}, J=6.0 \mathrm{~Hz}, 2 \mathrm{H}), 2.33(\mathrm{qi}, J=7.5 \mathrm{~Hz}, 2 \mathrm{H}), 2.10$ (qi, $J=$ $6.0 \mathrm{~Hz}, 2 \mathrm{H}), 2.03$ (d, $J=7.0 \mathrm{~Hz}, 3 \mathrm{H}) ;{ }^{13} \mathrm{C} \mathrm{NMR}\left(150 \mathrm{MHz}, \mathrm{CDCl}_{3}\right)$ $\delta 178.8,149.9,128.0,60.6,48.0,33.7,20.4,20.0,18.2,15.7$; IR (film) $v 2966,1641,1260,1156,1029 \mathrm{~cm}^{-1}$; MS (EI) $\mathrm{m} / z$ (rel \%) 149 (70) $\left[\mathrm{M}^{+}\right], 148(100)\left[\mathrm{M}^{+}-\mathrm{H}\right], 122$ (25); HRMS (EI) calcd for $\mathrm{C}_{10} \mathrm{H}_{15} \mathrm{~N}\left(\mathrm{M}^{+}\right)$149.1204, found 149.1194.

$( \pm)$-Tashiromine (66). $\mathrm{Pd} / \mathrm{C}(10 \%, 37 \mathrm{mg}, 0.034 \mathrm{mmol})$ was added to a solution of $56(48 \mathrm{mg}, 0.32 \mathrm{mmol})$ and $\mathrm{Na}_{2} \mathrm{CO}_{3}(36$ $\mathrm{mg}, 0.34 \mathrm{mmol})$ in $\mathrm{EtOH}(99 \%, 4 \mathrm{~mL})$ in a hydrogenation bomb. The bomb was purged with $\mathrm{H}_{2}(3 \times)$ then filled with $\mathrm{H}_{2}(1000$ psi) and the solution was stirred for $24 \mathrm{~h}$ ar room temperature, followed by filtration on Celite (EtOAc washings). The filtrate was concentrated, then resubmitted to the same hydrogenation conditions (37 $\mathrm{mg}$ of $10 \% \mathrm{Pd} / \mathrm{C}, 36 \mathrm{mg}$ of $\mathrm{Na}_{2} \mathrm{CO}_{3}, 4 \mathrm{~mL}$ of EtOH, $1000 \mathrm{psi}$ of $\mathrm{H}_{2}$ ) at room temperature for $72 \mathrm{~h}$. The reaction mixture was filtered on Celite (EtOAc washings) and the filtrate was concentrated. The crude material was purified by flash chromatography (basic alumina, 50:1 $\mathrm{CH}_{2} \mathrm{Cl}_{2}-\mathrm{MeOH}$ ) to give $42 \mathrm{mg}$ of a 20:1:2 inseparable mixture of $( \pm)$-tashiromine $(66)(73 \%, 79 \%$ corrected $)$, recovered starting material 56, and ( \pm )-epitashiromine (4\%), respectively, as a yellowish oil. The characterization of a small amount of separated pure $( \pm)$-tashiromine corresponds to the one previously reported. ${ }^{29 \mathrm{e}}$

Acknowledgment. We thank Ghislain Boucher for his early work on this project. This research was supported by the Natural Science and Engineering Research Council (NSERC) of Canada, FQRNT (Québec), the Canadian Fund for Innovation (CFI), and the Université de Sherbrooke. An NSERC doctoral fellowship to R.L.-G. and an NSERC predoctoral fellowship to F.B. are also gratefully acknowledged.

Supporting Information Available: Experimental procedures for compounds 9-13, 17, 18, 20-22, 25-32, 36, 38, 46, 48, 49, 51-53, 61, 62, and 64, as well as ${ }^{1} \mathrm{H}$ and ${ }^{13} \mathrm{C}$ NMR spectra for compounds 10-13, 17-22, 25-32, 36, 38, 46, 48, 49, 51-53, $61,62,64$, and 65 . This material is available free of charge via the Internet at http://pubs.acs.org.

JO052141V 